\title{
Avaliação das práticas ambientais em indústrias de laticínios - estudo de caso
}

\section{Evaluation of environmental practices in dairy industries - case study}

Evaluación de las prácticas ambientales en industrias lacteas - estudio de caso

Narjara Prates Gonçalves

Discente do curso de Engenharia Ambiental, UESB, Brasil.

narjara.prates@gmail.com

Talita Ruas Maderi

Professora assistente, UESB, Brasil.

taliruas@gmail.com

Pitágoras Fonseca Santos

Mestrando, UESC, Brasil. pitagoras-fonseca@hotmail.com 


\section{RESUMO}

As indústrias leiteiras vêm tendo um grande desempenho e importância econômica, social e ambiental. Diante dos estudos analisados e da sua importância no setor, surgem então problemas e preocupações ligados à qualidade e controle ambiental, além do elevado consumos de água. Com o objetivo de avaliar as práticas ambientais dessas indústrias de laticínios, desde sua recepção até a saída de seus produtos, foram realizados pesquisas e estudos exploratórios bibliográficos e posteriormente um check list como entrevista, para levantamento de dados e informações metodológicas e comparativas das empresas estudadas. o tratamento dos dados foi obtido a partir de uma análise descritiva, foi possível observar que o setor de produtos lácteos na região apresenta um potencial poluidor bem elevado. Além do desperdício de água e energia, a falta de padronização dos procedimentos higiênico-sanitários foi apontada também como ponto crítico, apresentando riscos ao meio ambiente se não avaliados e tratados corretamente.

PALAVRAS- CHAVE: Efluentes; Água; Produção mais Limpa.

\section{ABSTRACT}

The dairy industries have been performing well and are economically, socially and environmentally important. In view of the studies analyzed and their importance in the sector, there are then problems and concerns related to quality and environmental control, in addition to high water consumption. In order to evaluate the situation of these dairy industries, from their reception to the exit of their products, research and exploratory bibliographical studies were carried out and later a check list as interview, to collect data and methodological and comparative information of the companies Studied. With the treatment of the data obtained from a descriptive analysis, it was possible to observe that the dairy sector in the region presents an elevated pollutant potential. In addition to the waste of water and energy, the lack of standardization of hygienic-sanitary procedures proved to be critical points, presenting risks to the environment if not evaluated and treated correctly.

Keywords: Effluents; Water; Cleaner Production.

\section{RESUMEN}

Las industrias lácteas han tenido un gran rendimiento y la importancia económica, social y ambiental. Antes de los estudios analizados y su importancia en la industria, por lo que hay problemas y preocupaciones relacionadas con la calidad y el control del medio ambiente, y el alto consumo de agua. Con el fin de evaluar las practicas ambientales de estas industrias lácteas desde su recepción hasta la salida de sus productos se han llevado a cabo investigaciones y estudios exploratorios bibliográficas y luego una lista de verificación para la entrevista para la recolección de datos y el método de la lógica y la información comparativa de las empresas estudiados. Con el tratamiento de los datos obtenidos de un análisis descriptivo fue posible en cuenta que el sector lácteo en la región tiene un gran potencial de contaminación. Además de los residuos de agua y energía, la falta de estandarización de los procedimientos higiénico-sanitarios también monstró ser un punto crítico, con riesgos para el medio ambiente si no adecuadamente evaluado y tratado.

Palabras clave: Efluentes; Agua; Producción más limpia. 


\section{da Alta Paulista}

1. INTRODUÇÃO

As indústrias de laticínios no Brasil têm uma atuação de grande importância, tanto no aspecto econômico, quanto no social. Este setor é um segmento industrial bastante diversificado no âmbito nacional; onde encontra-se presente nos mesmos, empresas de leite de diversos portes, variando de empresas de fundo de quintal, que são beneficiadoras de volumes reduzidos de leite, até grandes multinacionais e cooperativas centrais capazes de processar um montante diário de centenas de litros de leite (JERÔNIMO et al, 2012).

O consumo dos produtos lácteos vem experimentando um grande crescimento mundial que levou a indústria a superar importantes obstáculos nos avanços tecnológicos e mudanças de hábitos em relação a melhorias para a empresa. Com esse novo cenário, as indústrias passam a tomar medidas de desempenho de padrões de qualidade e adotar funções ambientais, tornando-se um elemento importante na competitividade de mercado (SIQUEIRA, 2010).

As questões referentes ao meio ambiente têm ganhado um cuidado especial, devido à percepção dos impactos significativos que a produção e o consumo intenso causa à natureza. Os problemas ambientais presenciados hoje em dia, podem afetar tanto um impacto local, como em nível global. A intensificação da industrialização refletiu em um aumento na degradação ambiental, visto que os cuidados ambientais não são suficientes (BOSCO, 2013).

Bosco ainda comenta que, dentre as atividades industriais, o setor de alimentos destaca-se por um grande consumo de água e geração de efluentes significantes por unidade produzida. A indústria de laticínios é um exemplo relevante desse setor, na qual as operações de limpezas, tanques, pasteurizadores, homogeneizadores, tubulações, etc. geram um grande volume de efluente com elevada carga orgânica.

Diante das propriedades analisadas e sua importância neste setor, surgem então problemas ligados à qualidade e controle ambiental, além do elevado consumo de água. Os laticínios possuem um potencial poluidor muito alto, sendo que, possivelmente alguns efluentes cheguem a ser até cem vezes mais poluidores que o esgoto doméstico. Tornando-se um problema a ser enfrentado pelos fabricantes (SESSIN,2013).

Dentro deste contexto é facilmente perceptível que as empresas busquem estar em um exercício constante no que diz respeito às questões ambientais. Mesmo que as indústrias enfrentem uma série de dificuldades com a questão do meio ambiente, este setor é tratado por elas, como um compromisso secundário e de custo elevado, sendo muitas vezes, motivado pela pressão dos órgãos de controles fiscais (MARQUARDT et al, 2011).

Para Bacarji et. al. (2007), a indústria leiteira influencia diretamente e indiretamente nos aspectos e impactos ambientais, surge então a necessidade de prevenir e qualificar os processos de produção, propondo a implantação de tecnologias e métodos produtivos ambientalmente menos poluentes.

Contudo, a procura de boas práticas de produção e qualidade vem sendo atingida nas linhas produtivas das indústrias de lácteos, onde reflete a maneira sobre como estão sendo utilizados os recursos disponíveis e a qualidade dos resíduos depositados nos efluentes (WISSMANN, et. al. 2013).

\section{OBJETIVO}

Avaliar os métodos de produção das indústrias de laticínios quanto às práticas ambientais e procedimentos de qualidade, com foco no uso da água. 


\section{METODOLOGIA DA PESQUISA}

Inicialmente foi realizado um levantamento de dados das indústrias leiteiras da região sudoeste da Bahia, contendo informações básicas das empresas.

Para a realização do trabalho, os procedimentos adotados foram pesquisa exploratória bibliográfica, com o intuito de realizar um estudo preliminar sobre o problema que posteriormente seria investigado, de modo que a pesquisa, subsequentemente, pudesse ter maior compreensão e precisão e ser melhor concedida. E em seguida procedeu-se com a pesquisa experimental descritiva, com o propósito de estabelecer resultados a partir de dados primários, buscando sempre que possível a resolução dos problemas, melhorando práticas por meio de observações, análises e descrições objetivas.

Desta forma, para o levantamento de dados e informações metodológicas dos laticínios, foi desenvolvido um questionário em forma de check list semiestruturado, com 31 perguntas elaboradas em sequências básicas e dividida em tópicos como informações gerais da indústria e suas condições ambientais, para uma melhor compreensão e organização. Seu preenchimento foi realizado através de visita técnica entre duas empresas. Para isso, as indústrias foram antecipadamente contactadas por telefone, a fim de um agendamento para a coleta de dados.

Para a caracterização do setor e a elaboração dos informativos durante a visita local, a entrevista foi feita com um responsável pela empresa e funcionários encarregados por cada setor, para um melhor entendimento do processo de instalação e higienização da fábrica. Assim, analisando a matéria-prima e insumos, pode-se qualificar e quantificar as atividades de produção dos laticínios, verificar as condições higiênico-sanitária do local, bem como seus impactos ao meio ambiente, principais problemas e dificuldades encontradas pela mesma.

Por fim, foi realizada uma avaliação do processo de produção e mediante a elaboração de fluxograma produtivo geral e de cada subproduto, sendo possível analisar e abordar todas as etapas e identificar cada ponto, tanto nas condições do ambiente local, bem como a sua higienização e controle de qualidade, quanto ao que diz respeito ao meio ambiente e suas vertentes.

Após os dados obtidos, foi possível gerar um estudo e estabelecer cenários, analisando as informações adquiridas de forma descritiva, e as apresentando e articulando através de textos, gráficos e tabelas comparativas.

\section{RESULTADOS E DISCUSSÃO}

Aplicando-se a metodologia planejada, foi possível fazer uma comparação referente a duas indústrias de laticínios visitadas. Durante as visitas técnicas a finalidade do planejamento foi integralmente cumprida. A seguir, são mostrados dados gerais das empresas visitadas, aqui relacionadas por INDÚSTRIA A e INDÚSTRIA B. No qual, se baseavam na aplicação de check-list para avaliar e observar os dados operacionais sobre as condições do local de trabalho, quanto ao aspecto geral de fabricação, aspectos gerais de limpeza e sanificação e o comprometimento e preocupação com o meio ambiente.

O acompanhamento do leite nos laticínios, mostra que o recebimento varia cerca de dois mil litros por dia em ambas as indústrias (figura 1 ). 
Figura 1: Recebimento e a capacidade de processamento do leite nas indústrias A e B.

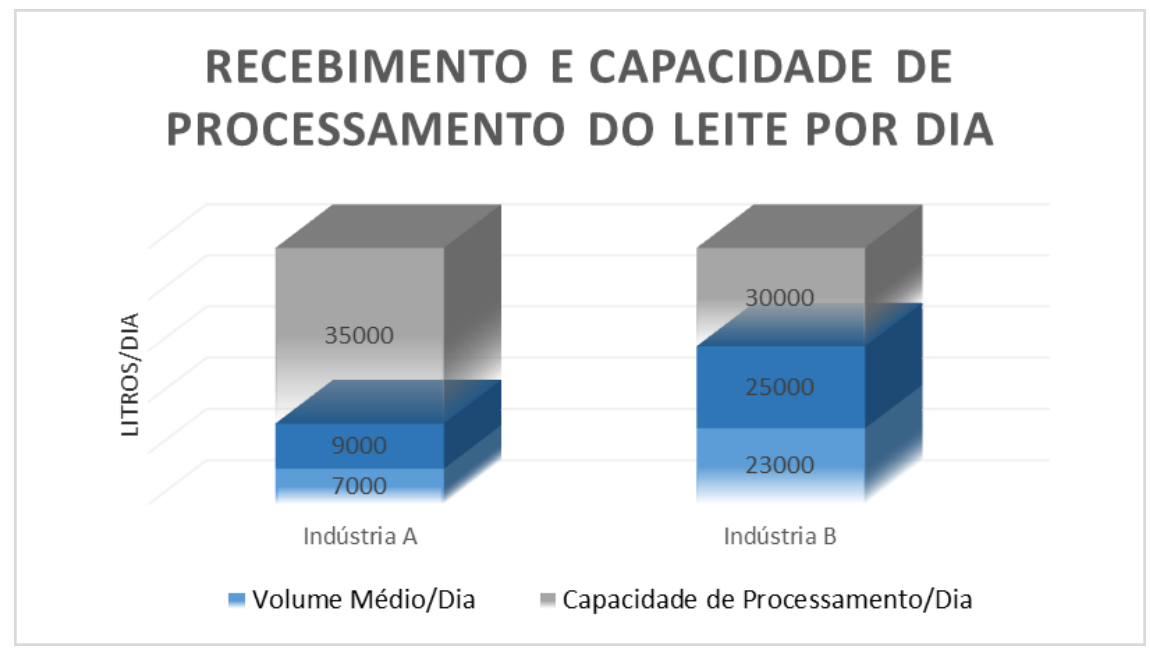

Fonte: Dados da pesquisa

Tanto a Indústria A, quanto a Indústria B recebem o leite "in natura", colhido de tanques de refrigeração, em caminhões próprios da empresa. Os caminhões são isolados termicamente para manter o leite a baixa temperatura de forma a chegar nas fábricas sem risco de perda de qualidade, quanto à acidez.

Produtos da Indústria A: leite pasteurizado, queijos (mina frescal, mussarela, minas padrão, prato, provolone, qualho, parmesão, parmesão ralado), frescal, ricota e ricota de búfala, iogurte, bebida láctea e manteiga.

Produtos da Indústria B: leite pasteurizado, queijos (minas, mussarela, parmesão, prato), ricota e manteiga. Os queijos coalho e frescal estão em fase de teste de produção e venda.

O volume médio de leite recebido chega entre 7000 a 9000 Litros/dia na Indústria A e sua disposição de processamento é de 35000 litros/dia. Já na indústria $B$, o recebimento tem um volume médio entre 23000 e 25000 litros/dia e sua capacidade de processamento chega a 30000 litros/dia.

Quanto as condições das instalações físicas (tabela 1), é possivel comparar as emempresas quanto as condições das instalações físicas e os aspectos gerais de fabricação.

Tabela 1: Quadro comparativo quanto as condições físicas dos laticínios A e B.

\begin{tabular}{l|c|c}
\hline Setor & INDÚSTRIA A & INDÚSTRIA B \\
\hline Caldeiras & Quant.: 2 / Bom & Quant.: 1 / Bom \\
\hline Câmeras Frias & Quant.: 2 /Bom & Quant.: 6 /Bom \\
\hline $\begin{array}{l}\text { Lavatórios na área de } \\
\text { processamento }\end{array}$ & Bom & Bom \\
\hline $\begin{array}{l}\text { Tubulações estão em boas } \\
\text { condições }\end{array}$ & Bom & 'Ruim \\
\hline
\end{tabular}


Fonte: Dados da pesquisa.

Devido ao período de seca na região, as indústrias têm recebido uma baixa quantidade de leite, consequentemente diminuindo o uso de equipamentos de alto consumo. Na INDÚSTRIA B, somente uma caldeira está ativada, com outras duas desligadas. Como combustível, é utilizado a lenha do eucalipto com nota fiscal em ambas as indústrias, com bom estado de uso. Já na INDÚSTRIA A, somente duas câmeras frias estão acionadas e em uso com bom estado de conservação.

Durante a visita foi percebido na Indústrias B, um vazamento da tubulação, além de algumas partes estarem enferrujadas, onde conduzia água gelada na fabricação de queijos. Enquanto que na Indústria $A$, foi verificado também paredes e tetos em estado de deterioração e descascando, com bastante umidade onde está localizada o tanque de fabricação dos queijos. Num processo de produção as indústrias de laticínios devem considerar como fator muito importante a qualidade do produto, a limpeza do ambiente e higienização por completo. Tudo isso depende de treinamento e da mão-de-obra para promover um atributo em processo. A implantação das metodologias e ferramentas específicas do setor como BPH (Boas Práticas de Higiene), BPF (Boas Práticas de Fabricação) e APPCC (Análise de Perigos e Pontos Críticos de Controle) são importantes ferramentas para o avanço da qualidade do produto (SCALCO, et. al 2001).

No que diz respeito aos procedimentos para a qualidade nas empresas, os essenciais são aqueles relacionados à segurança do alimento. Entre as principais ferramentas da qualidade utilizadas pelas indústrias A e B destaca-se: Boas Práticas de Fabricação, Procedimento Padrão de Higiene e Organização e Análise de Perigos e Pontos Críticos de Controle. Como meio de garantir a qualidade de produtos alimentícios fazendo-se necessário atender duas condições fundamentais, como a segurança do alimento e as especificações requisitadas pelo consumidor.

Com relação à verificação do cumprimento das normas e padrões de qualidade, a Indústria $A$ possui registro SIE e a Indústria $B$, registro SIF. Além de receberem visitas regulares de órgãos fiscalizadores, sanitário e ambiental a ADAB (Agência de Defesa Agropecuária da Bahia), MAPA, INEMA (Instituto do Meio Ambiente e Recursos Hídricos) e IBAMA (Instituto Brasileiro do Meio Ambiente e dos Recursos Naturais Renováveis).

Quanto a higienização nas instalações temos para a INDÚSTRIA A o processo de limpeza (figura 2) que consiste em pré-lavagens, lavagem e enxague.

Figura 2: Higienização das instalações da Indústria A e os insumos utilizados. 


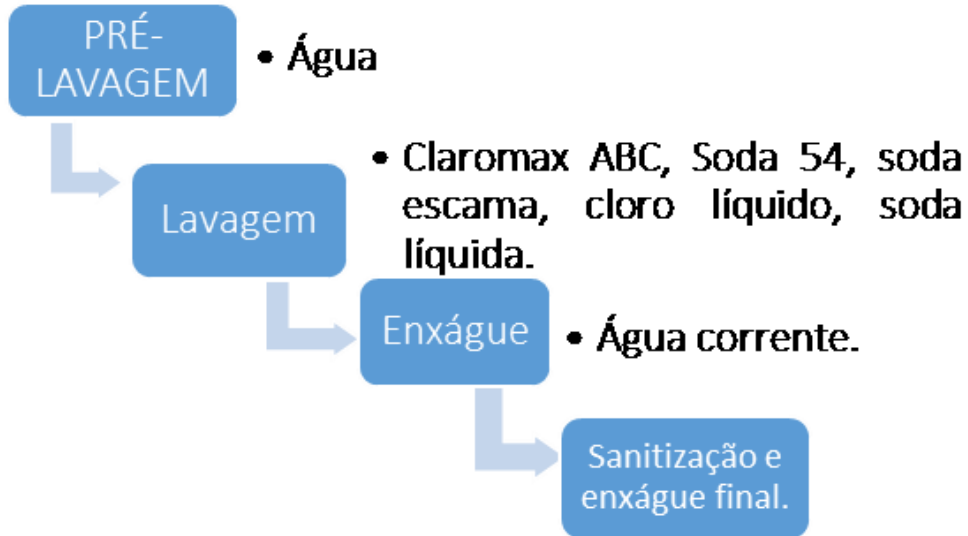

Fonte: Dados da pesquisa.

A primeira etapa consiste na pré-lavagem, onde é utilizado somente água para a remoção total dos resíduos visíveis. A segunda etapa é a lavagem, onde através de produtos químicos, ocorre a significativa redução de microrganismos. Para essa higienização são utilizados agentes de limpeza e desinfecção, tais como o Cloro, soda 54, soda escama, soda líquida e cloro líquido (Hipoclorito de sódio). Logo em seguida, no processo de enxágue é utilizado uma circulação maior de água para a remoção dos resíduos de lavagem. É importante salientar o uso de bicos em mangueiras visando à redução de consumo de água durante todos os procedimentos. A sanificação e enxágue final incide na reduz os microrganismos e remoção dos resíduos de agentes sanitizantes. Essa limpeza é feita diariamente ao fim de todo expediente. E uma vez ao mês é feita uma limpeza profunda em todo o ambiente.

$\mathrm{Na}$ indústria B (figura 3), é utilizado o sistema de limpeza CIP (Clean in Place), que, segundo Forni (2007), consiste em um método usado para a limpeza das máquinas de envase e equipamentos de processamento, como os tubos sanitários, tanques, etc. circulando-se automaticamente, passando em uma tubulação com água, outra com ácido e outra com soda cáustica. Passando então por soluções de enxágue até a limpeza total e sanitização em circuito fechado, ou seja, sem a mínima remoção de componentes do sistema para esta tarefa.

Figura 3: Higienização das instalações da Indústria B. 


\section{da Alta Paculista}

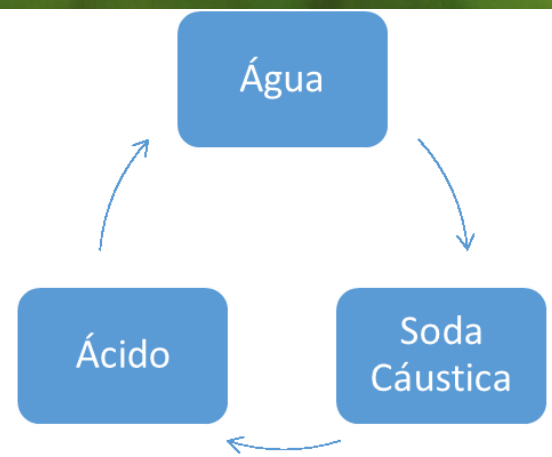

Fonte: Dados da pesquisa.

O processo de higienização é dividido em quatro etapas sequenciais: a primeira delas é o préenxágue da linha produtiva, com uma duração de 5 minutos, onde é realizado com a solução do tanque de água. Esse processo requer que a água esteja circulando por todo o sistema a uma certa temperatura. Fazendo com o que a o resíduo total do leite e do soro sejam empurrados para a próxima etapa. A segunda etapa é com banho com agente alcalino, utilizado como detergente, circulando por todo o sistema por 15 minutos a uma temperatura máxima de $95 \circ \mathrm{C}$. A terceira etapa é o enxágue intermediário, que requer a água circulando pelo sistema todo na temperatura ambiente e com finalidade de remover a maior parte do produto alcalino remanescente no sistema para que não diminua a eficiência do agente ácido. A quarta etapa consiste no banho com agente ácido, que circula pelo sistema todo a uma temperatura máxima de 80 ํ C a 95 ㄷ. E por último o enxágue final, este ciclo implica na circulação de água por todo o sistema a temperatura ambiente e tem a finalidade de remover todo e qualquer vestígio dos produtos utilizados nos ciclos anteriores. A água a ser utilizada neste ciclo deverá atender as mesmas exigências da água que será utilizada na fabricação.

Esse processo de higienização é feito todos os dias de trabalho, ao final de expediente.

Quanto as condições do meio ambiente, (tabela 2) foi possível realizar um comparativo sobre os aspectos gerais de limpeza e sanificação e o comprometimento e preocupação com o meio ambiente.

Tabela 2. - Quadro comparativo quanto as condições de meio ambiente dos laticínios A e B.

\begin{tabular}{l|c|c}
\hline \multicolumn{2}{c}{ INDÚSTRIA A } & INDÚSTRIA B \\
\hline Resíduo produzido & $\begin{array}{c}\text { Água residual, sobra de produção, } \\
\text { embalagem e material de escritório }\end{array}$ & $\begin{array}{c}\text { Água residual, sobra de } \\
\text { produção, embalagem e }\end{array}$ \\
\hline
\end{tabular}




\begin{tabular}{|c|c|c|}
\hline & & material de escritório \\
\hline $\begin{array}{l}\text { Destino das sobras das } \\
\text { embalagens }\end{array}$ & Reciclagem & Coleta municipal \\
\hline Destino final dos efluentes & Rede de esgoto Municipal & Rede de esgoto Municipal \\
\hline $\begin{array}{l}\text { Fonte de abastecimento de } \\
\text { água }\end{array}$ & Rede Municipal & $\begin{array}{c}\text { Sistema próprio: poço } \\
\text { artesiano e rede municipal }\end{array}$ \\
\hline $\begin{array}{c}\text { Processo onde mais se } \\
\text { utiliza água }\end{array}$ & $\begin{array}{c}\text { Lavagem, embalagem, fabricação da } \\
\text { Manteiga e Parmesão }\end{array}$ & $\begin{array}{l}\text { Lavagem, fabricação da } \\
\text { Manteiga e Parmesão }\end{array}$ \\
\hline Fonte de energia utilizada & Empresa de Eletricidade do Estado & $\begin{array}{c}\text { Empresa de Eletricidade do } \\
\text { Estado }\end{array}$ \\
\hline $\begin{array}{c}\text { Quantidade média do gasto } \\
\text { de energia ( } R \$ \text { ) }\end{array}$ & $27.000,00$ (vinte e sete mil reais) & $20.000,00$ (vinte mil reais) \\
\hline $\begin{array}{l}\text { Projeto de desempenho } \\
\text { ambiental }\end{array}$ & Não & Sim \\
\hline Licenciamento Ambiental & Sim & Sim \\
\hline
\end{tabular}

Fonte: Dados da pesquisa.

Em relação a Indústria $A$, todas as sobras do processamento de outros queijos é misturada no produto 'parmesão com outros' e a água que passa na filadeira para o creme é utilizada para a manteiga, tornando as águas residuais bastante aproveitável. Toda a sobra de embalagem vai para a reciclagem. Já a Indústria B, não reutiliza sobras de produtos e as águas residuais são descartadas em rede de esgoto municipal.

Na Indústria $B$, possui uma estação de tratamento de água (ETA) na própria empresa, onde realiza a purificação da água captada do poço próximo a indústria para torná-la própria para o consumo.

Na ETA, o processo ocorre em algumas etapas: coagulação, floculação, decantação, filtração, desinfecção, correção de pH.

Conforme Babosa et al (2009), em sua pesquisa também feita em forma de questionário, foi observado que os resíduos sólidos gerados no laticínio eram compostos basicamente de embalagens plásticas, papeis do escritório, embalagens de produtos químicos, aparas de queijos, lixo dos banheiros e cinzas de caldeiras. Os resíduos sólidos gerados no laticínio como papelão e plásticos são queimados no final do dia, em um determinado local, de forma não controlada. As cinzas geradas na fornalha do gerador de vapor são dispostas sobre o solo.

A empresa tem projetos de desempenho ambiental no laticínio, onde programa a reforma na estrutura dos laticínios com melhoramento na parte ambiental, fazendo troca de aparelhos antigos, para a utilização de equipamentos mais modernos e com menos consumo de energia. Além da estação de tratamento de água, a indústria planeja implantar futuramente uma estação de tratamento de esgoto.

No que diz respeito à limpeza dos caminhões de transporte do leite, são feitas nas dependências locais das duas indústrias, não possuindo adaptação para limpeza automática, sendo esta realizada manualmente, consumindo grandes volumes de água. $O$ procedimento de 


\section{da Alta Paulista}

higienização visa a execução de tarefas básicas, tais como a drenagem e enxágue para retirada de resíduos, uso de detergentes alcalino e ácido e água a temperatura elevada, enxágue, procedimento de sanitização e enxágue final com o uso de mangueiras, sendo esta realizada manualmente, consumindo assim, grandes volumes de água.

\subsection{Aspectos e impactos ambientais dos locais de estudo}

Conforme a definição na norma BR ISO 14001, aspecto ambiental é "elemento das atividades, produtos ou serviços de uma organização que pode interagir com o meio ambiente", onde pode-se englobar a emissão, descarga, consumo ou reutilização de um material, ou ainda de ruído que é emitido por alguma atividade. Definindo o impacto ambiental, trata-se de uma alteração no meio ou em partes, sendo benéficas ou danosos, por determinada ação, produtos ou atividade.

De acordo com o estudo realizado nos laticínios visitados, devido as suas atividades, é possível detectar problemas ambientais decorrente dos seguintes aspectos: efluentes líquidos e sólidos, material de limpeza, papelão, plásticos, e resíduos de soro e queijos.

De forma geral, é possível notar que os principais impactos ambientais das duas indústrias de laticínios estão relacionados ao lançamento dos efluentes líquidos, à geração de resíduos sólidos e emissões atmosféricas, geralmente sem nenhum tipo de controle ou tratamento (BARBOSA et al, 2009).

Observando que embora na indústria $A$ todas as sobras de outros queijos sejam misturadas em um outro produto e a água da filadeira seja reutilizada adequadamente para o preparo da manteiga. O que torna as águas residuais bastante aproveitável e o envio de sobras de embalagens para a reciclagem.

Além disso, foi observado que para os equipamentos não há programa de manutenção e melhorias durante o processo e minimização de resíduos. Com isto, tem-se aumento significativo, principalmente da presença de matéria orgânica no efluente final.

Conhecendo as vertentes principais de cada uma, observou-se então, que os setores de produção lácteos apresentam um potencial poluidor muito grande. Além do desperdício de água e energia e a falta de padronização dos procedimentos higiênico-sanitários serem pontos críticos apresentados. A produção de leite e produtos subsequentes, tanto na forma líquida quanto na forma de efluentes sólidos, apresentaram riscos ao meio ambiente se não avaliados e tratados corretamente.

Deve-se ressaltar também que a maior ausência deparada na gestão da qualidade está diretamente relacionada ao treinamento apropriado de funcionários e o controle de processos produtivos.

Para tomar medidas corretas de prevenção e melhoramento é necessário oferecer cursos e treinamentos para funcionários, padronizar o processo de higienização e a manutenção de equipamentos regulares, consumir de forma racional a água e destinar de forma apropriada os resíduos sólidos e líquidos gerados nas empresas.

Além do tratamento e manejo correto, é importante também, minimizar a geração dos resíduos. A utilização de boas práticas que reduzam o consumo da água e, portanto, a produção de efluente é de extrema relevância, e coerente com o padrão de desenvolvimento sustentável que preserve o meio ambiente. Pequenas ações como evitar torneiras e 
mangueiras abertas, desligar aparelhos e máquinas que não estão em uso, com isso, tem-se redução na geração de efluentes e diminui custos para o tratamento (SARAIVA et al, 2012).

\section{CONCLUSÃO}

Com a comparação feita entre as indústrias de laticínios foi possível analisar e caracterizar cada setor, esperando-se compreender o efeito do beneficiamento do leite e seus derivados, bem como os problemas e dificuldades enfrentados pelas indústrias quanto as questões de higiene e às praticas ambientais, já que ambas influenciam diretamente na qualidade da água. Para reverter esse cenário é necessário adotar medidas mitigadoras, através de adequações e melhorias relativamente simples e que venham a proporcionar um menor impacto negativo sobre o meio ambiente. Tais medidas podem ser maior controle do consumo de água e do uso dos produtos utilizados para higienização; separação mínima dos resíduos sólidos recicláveis e sua entrega para empresas de reciclagem; treinamento constante dos funcionários em relação ao uso racional de todos os insumos; melhor utilização dos procedimentos de controle sanitário, que permite maior padronização do processo e desta forma permite maior economia de insumos, menos desperdício e inclusive menos gastos financeiros.

Contudo, faz-se necessário que também haja uma avaliação aprofundada dos impactos negativos ocasionados no lançamento dos efluentes no ambiente. Tendo em vista que, para uma melhor regularização ao processo de produção, é preciso que este seja sustentável, possibilitando o tratamento correto dos efluentes antes do lançamento nos corpos hídricos.

\section{REFERÊNCIAS BIBLIOGRÁFICAS}

BACARJI,A. G., HALL, R. J., ZANON, H., Os Impactos da Sazonalidade da Produção de Leite numa Indústria de Laticínio no Estado de Mato Grosso do Sul. Dourados, MS-Brasil. 2007.

BARBOSA, C. S Mendonça, R. C. S, Santos, A. L. Pinto, M. S. Aspectos e Impactos Ambientais envolvidos em um Laticínio de Pequeno Porte. Rev. Inst. Latic. "Cândido Tostes", Jan/Fev, no 366. 2009.

BOSCO, W.A. Programa de Produção Mais Limpa em uma Indústria de Laticínios de Médio Porte. Universidade Federal de Santa Catarina- UFSC Curso de Graduação de Engenharia Sanitária e Ambiental, Florianópolis, SC 2013, 109 p.

FORNI, R. Projeto Mecânico De Um Sistema De Higienização Cip (Cleaning In Place). Universidade de São Paulo Escola Politécnica. 2007.

JERÔNIMO, C.E.M., COELHO, M.S., MOURA, F.N., ARAUJO, A. B. A., Qualidade Ambiental e Sanitária das Indústrias de Laticínios do Município de Mossoró-RN, Rev. Elet. em Gestão, Educação e Tecnologia Ambiental, v(7), no 7, p. 1349-1356. 2012.

MARQUARDT, L., ROHLFES, A. L. B., BACCAR, N.M., OLIVEIRA, M. S. R., RICHARDS, N. S. P. S. Indústrias Lácteas: Alternativas de Aproveitamento do Soro de Leite como Forma de Gestão Ambiental. Revista do depto. de Química e Física, v. 15, n. 2. 2011.

SARAIVA, C. B., Magalhães, F. A. R., Moreira, V. E., B, S. O. Aspectos Ambientais Da Produção Do Queijo Minas Artesanal. Rev. Inst. Latic. "Cândido Tostes", no 388. 2012.

SCALCO, A. R.; TOLEDO, J. C.; A. Gestão Da Qualidade Em Laticínios Do Estado De São Paulo: situação atual e recomendações. 2001.

SESSIN, L. E. Programa de produção mais limpa em uma indústria de médio porte de laticínios. 2013. 


\section{da Alta Paulista}

SIQUEIRA, K. B. CARNEIRO, A. V.; ALMEIDA, M. F. de; SOUZA, R. C. N. O Mercado Lácteo Brasileiro no Contexto Mundial. EMBRAPA, p. 18, Juiz de Fora- Minas Gerais. 2010.

WISSMANN, M.A.; HEIN, A.F.; NEULS, H. Geração de resíduos: uma análise da ecoeficiência nas linhas de produção em uma indústria de laticínios e a influência sobre os custos ambientais. 2013. 